\title{
Application of the Geological Strength Index in Peruvian underground mines: retrospective 18 years after its implementation
}

\author{
LA Mejia Camones RockEng Inc., Canada \\ C Chacon Nunez Pan American Silver, Peru
}

\begin{abstract}
Historically, underground Peruvian mining has been considered high-risk work. In 2000, 55 fatal accidents were reported and this number increased to 74 in 2002. Rockfall is the cause of around $30 \%$ to $40 \%$ of these incidences. In 2000, changes within company work policies were done in order to increase the safety and productivity in underground excavations. Thus, geomechanical departments were implemented in order to improve mine planning, to optimise the use of rock supports, to zone the mine according to the rock mass quality and to increase safety levels by reducing accidents due to rockfall. Regarding the use of rock mass quality technique, some companies chose the Q-index (Barton et al. 1974) and others chose the Rock Mass Rating (RMR) (Bieniawski 1979) to perform geomechanics in the mining operations. While these geomechanical classification indices improved the operation, they were not suitable for general use by workers, principally because several of the input parameters had to be determined using technical knowledge. It was important to find a rating system that allowed all workers to be able to evaluate the risk before entering an excavation and/or determining if the excavation needs support. Accordingly, the Geological Strength Index (GSI; Hoek \& Brown 1997) was chosen as the best option. In 2002, the practical mining support (SPM) table was introduced (Vallejo, 2002) and the GSI table-including the support types associated with the rock mass quality - was implemented. This new table was easy to be learn and read, and allowed all operational workers to be able to evaluate the rock mass and allowed the geomechanical engineers to integrate all the information of the mine into a single geomechanical classification system. This paper aims to address the process of implementing the GSI in underground Peruvian mining, as well as presenting the process of construction of the Geomechanical Tables and the impact that this system has in the reduction of accidents and in productivity improvements. Currently, after 18 years, almost all Peruvian underground mines have adapted the GSI table for their operations and consider the GSI table part of the worker's personal protective safety equipment.
\end{abstract}

Keywords: rock mass classification, Geological Strength Index, Geomechanical Tables

\section{Introduction}

During the last 20 years, fatal accidents in Peruvian mining operations have been decreasing while their production has increased. The implementation of a safety mining system and the incorporation of geomechanical departments at mine sites have played an important role in the reduction of accidents. Historically, Peruvian underground mines are considered a high-risk worksite where rockfall are the main cause of fatal accidents. In 2000, 55 fatal accidents were reported and this number increased to 74 in 2002. Rockfall was the cause of around $30 \%$ to $40 \%$ of these incidents (Figure 1). Several factors can be considered when evaluating rockfall problems such as incorrect work procedures, deficient ground condition evaluations, human error etc. However, all of them can be associated to the rock mass evaluation. In the past, concepts of rock mechanics were rarely used to evaluate rock masses, to determine maximum spans and/or to define adequate ground support for the excavations. Commonly, there was no standard procedure for ground control and it depended on the experience of the engineers responsible for the excavation. Different points of view and experience among engineers could result in divergent rock mass evaluations and 
create confusion among the workers. The results were excavations over supported (highly expensive), poorly supported (highly risk) or over excavated (dilution).

Geomechanical departments begin to be implemented in underground mining

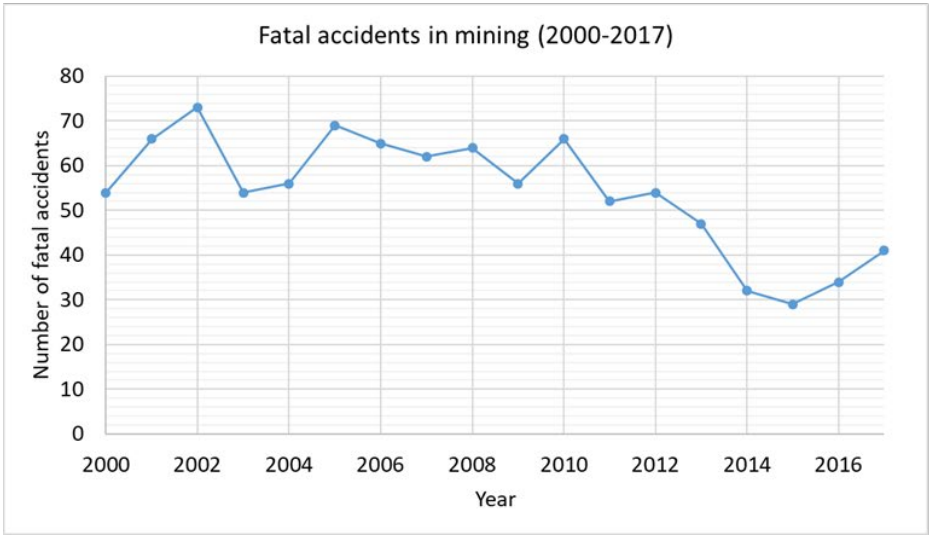

(a)

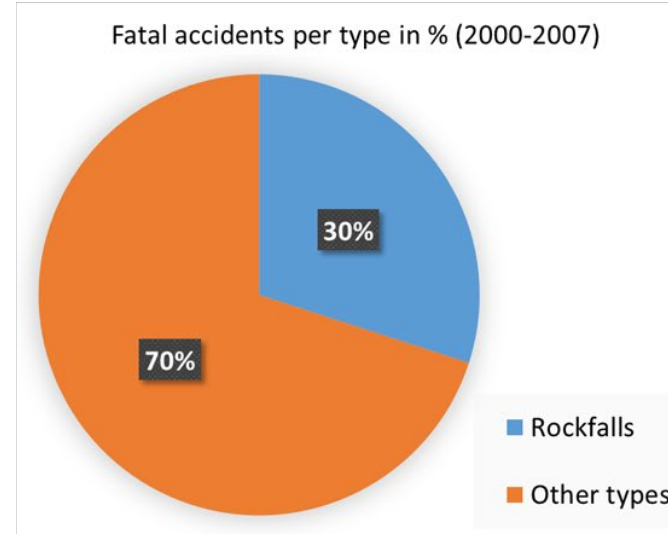

(b)

Figure 1 (a) Number of fatal accidents in Peruvian mines during the period 2000-2017; (b) Fatal accidents per type in \% at the same period. Rockfall represents $30 \%$ of the total

The mining methods used also contributed to the high number of accidents. In 2000, most Peruvian underground mines were conventional unmechanised mines. Normally, work tasks are allocated to workers at the beginning of shift. However, due to the difficulty of travelling between stopes in a conventional mine, engineering supervisors arrived at the worksite after work had started and after the initial evaluations of the ground conditions had been completed by the work team. Once again there are different levels of experience, backgrounds and non-technical knowledge.

Thus, several underground mining companies started to implement Geomechanical Departments in their operations between 2000 and 2006. The main goals of these departments can be summarised as:

- To create a geomechanical zoning of the mine.

- To optimise spans and ground support.

- To assist mine planning.

- To reduce the risk of instabilities in underground excavations and consequently, to reduce the number of accidents due to rockfall.

Rock mechanics classifications were an important part in achieving these goals. However, as will be described in the following sections, due to the technical knowledge needed to use rock mass indices and the difficulties for geomechanical engineers to supervise all the excavations in conventional underground mines, it was necessary to provide geomechanical tools to the workers to allow them to perform the initial evaluation of the excavation stability.

\section{Introduction of the Geological Strength Index in underground Peruvian mines}

The rock mass classification can be described as a checklist that includes all relevant information about the rock mass. The most common classification systems require input such as the strength of intact rock, Rock Quality Designation (RQD), the spacing, orientation and condition of discontinuities, groundwater and stress state. The rock mass classification determines a 'quality index' to be assigned to the rock mass using field 
observations and some laboratory tests. This 'quality index' can be related to geomechanical parameters of the rock mass and with the rock support types to be used within rock excavations.

At the end of the 1990s and beginning of 2000s, the most common indices used in tunnelling, the Rock Mass Rating (RMR; Bieniawski 1979, 1989) and Q-index (Barton et al. 1974), were introduced in some underground mines. Thus, new types of ground support were introduced to reduce the use of wood (the main type of ground support used in conventional underground mines) and to optimise the mining cycle. Geomechanical departments adopted the procedures from civil tunnel construction for mapping and supervising underground excavations, as well as to zone the rock masses. To reduce the number of accidents, geomechanical engineers created the protocol of evaluating the ground condition before the beginning of operations, of defining the ground support to be applied and of performing the geomechanical mapping of excavations. However, geomechanical engineers soon realised that these tasks were impossible to be executed due to the limited number of geomechanical engineers (i.e. in 2005, Morococha Mine had over 50 stopes distributed in three operations and only two geomechanical engineers). Incident and accidents due to rockfall continued to occur in underground excavations impacting the confidence in the geomechanical department implementation. It was necessary to find a better way to achieve the goals of the geomechanical departments and the choice of an adequate rock mass classification system played an important role. The proposed solution can be summarised in the following steps:

- Find an adequate rock mass classification index which allows excavations to be qualitatively evaluated in a short time, and also define the ground support and the maximum span permissible.

- Integrate this rock mass classification with mapping of excavations and with supervisory procedures.

- Introduce this rock mass classification for all workers to reduce the number of accidents due to rockfall.

The last step was very important. It was necessary to find an adequate rock mass classification which could be used by all workers with different levels of knowledge in rock mechanics. The main idea was that all workers would be able to evaluate the conditions of the excavations previously to the beginning of operations. The number of parameters involved, and the technical knowledge required for the $Q$ and RMR indices made their implementation difficult. Thus, the Geological Strength Index (GSI), introduced by Hoek \& Brown (1997) and Hoek et al. (1995), became the best option (Figure 2(a)). The correlations between the $Q$, RMR and GSI indices, allowed definition of the type of rock support using the GSI. Between 1999-2002, Vallejo $(1999,2002)$ introduced the GSI tables in underground mining operations by modifying the original GSI table to include the intact rock strength as an input parameter (Figure 2(b)). This table is called the GSI Modified Table. Based on mining experience and observations of the excavations ground response, Vallejo modified the original ground support table (Barton et al. 1974). The new table, called 'Table of Practical Mining Ground Support' (SPM in Spanish), includes the types of ground support commonly used in Peruvian underground mines (Figure 3).

The introduction of the GSI Modified Table in underground Peruvian mines had a great impact in underground mining excavations due to its ease of use by all mine workers. It was first introduced in Cerro de Pasco, San Vicente, San Genaro, Chungar y Poderosa Mines (Vallejo 2002). Initially the use of the GSI Modified Table was refused by engineers and workers that were used to working without geomechanical concepts. Other simplifications in the GSI Modified Table were suggested in order to facilitate their inclusion in the workflow. 


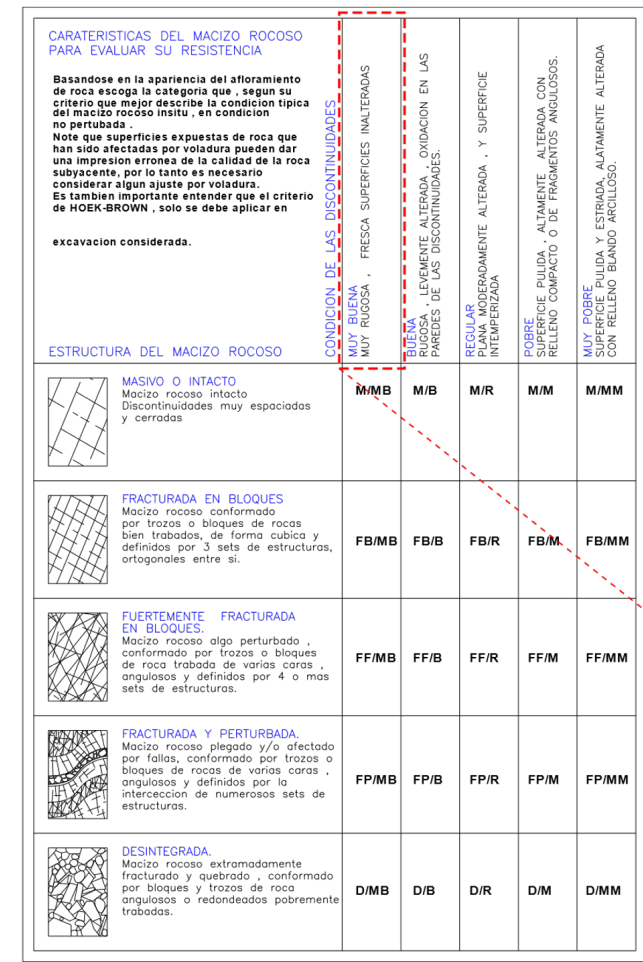

(a)
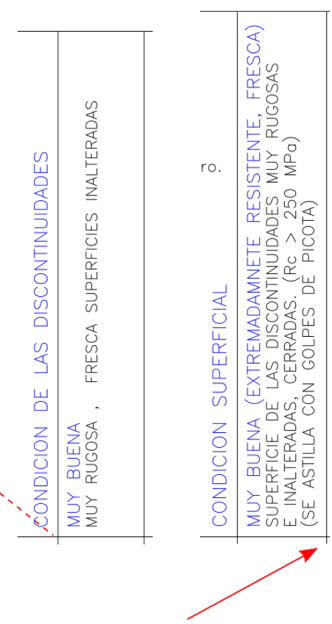

Inclusion of the UCS (from field test) of intact rock in the GSI table

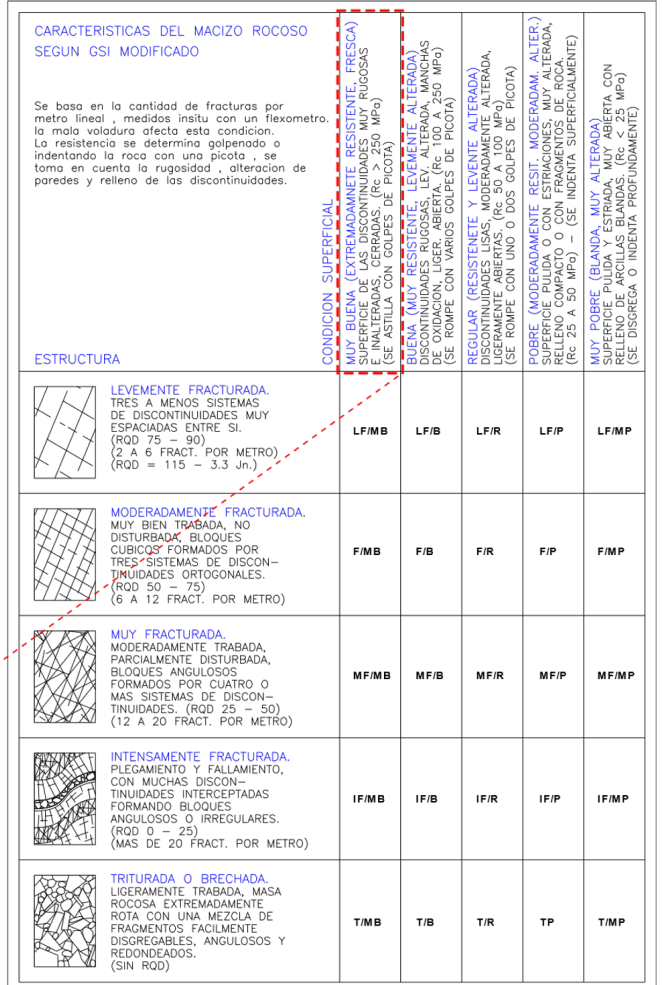

(b)

Figure 2 Introduction of the GSI table in Peruvian underground mines (tables in Spanish). (a) Original GSI table proposed by Hoek \& Brown (1997); (b) GSI Modified Table proposed by Vallejo (2002) to be applied in underground mines in Peru

$$
\begin{aligned}
& \text { Inclusion of the GSI-index and } \\
& \text { common ground support used in } \\
& \text { Peruvian underground mines }
\end{aligned}
$$

Q empirical support design (after Barton 1974)

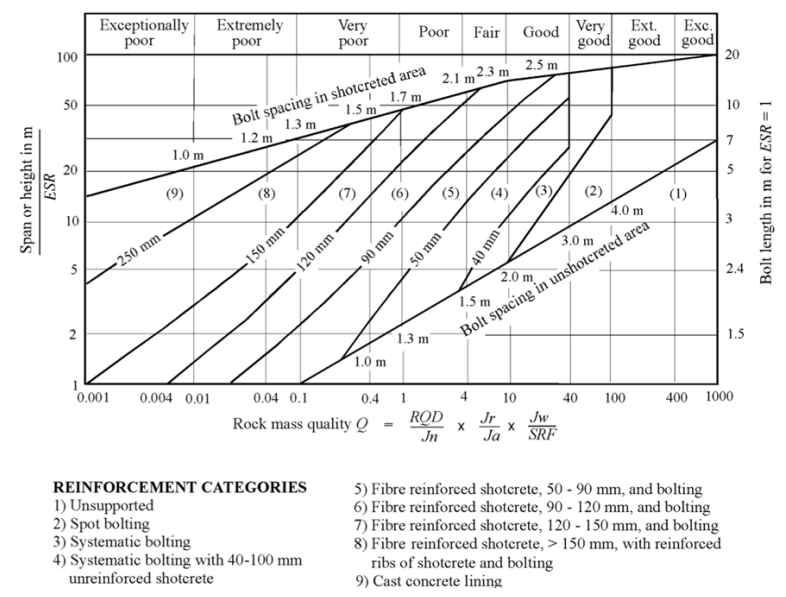

(a)

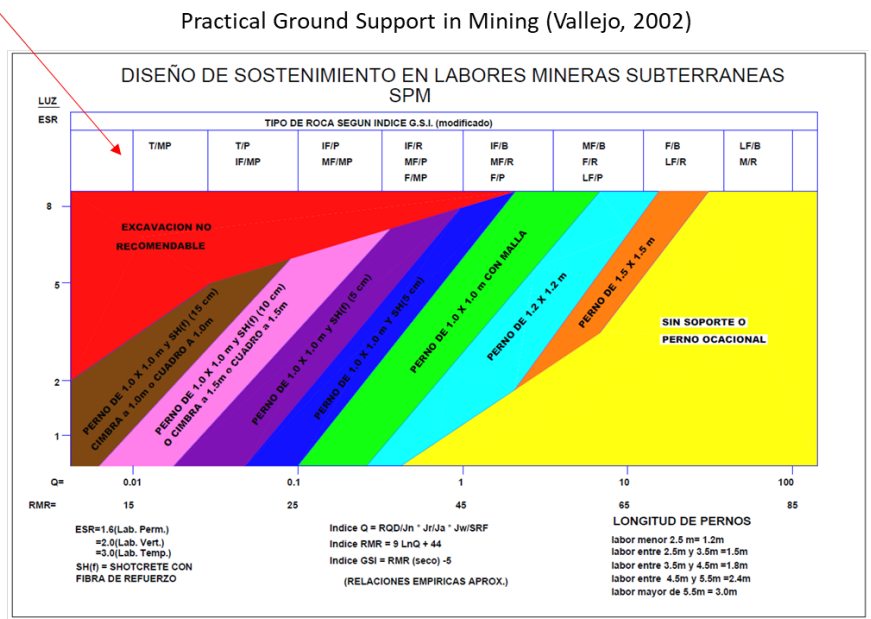

(b)

Figure 3 Practical ground support in underground mines (Vallejo 2002). (a) Empirical support design using Q-index (after Barton et al. 1974); (b) Practical Ground Support in Mining table (SPM in Spanish) - modification of the empirical ground support table to include the GSI and ground support types used in Peruvian underground mines (table in Spanish) 


\section{Geomechanical tables and their implementation}

The GSI Modified Table and the SPM Table were complex to be implemented for all workers. Evaluating two tables required more work, required math calculations to define the value of span/ESR and required line drawings to define the ground support. Therefore, simplifications were made to facilitate their use. For that, both SPM and GSI Modified tables were merged in one new GSI table called the Geomechanical Table (Figure 4). The Geomechanical Table provides the workers with information about the geomechanical conditions of the rock masses and the ground support recommended to stabilise the excavation. It contains the rock mass geomechanical characteristics of a specific ground. This means that each mine should have its own Geomechanical Table. and it should be associated with the most common type of rock masses encountered in situ and with the types of rock support commonly used in the operations. An example of the Geomechanical Table application for underground mines can be found in Morococha Mine during 2005-2008 (Pan American Silver Peru). Two types of Geomechanical Tables were developed for specific types of excavation. The first one, used in developments, uses only four types of rock mass structure and the second one, used in stopes, uses three types of rock mass structure. These tables, account for rock mass structure encountered in this specific site, which simplifies the application of the Geomechanical Table.
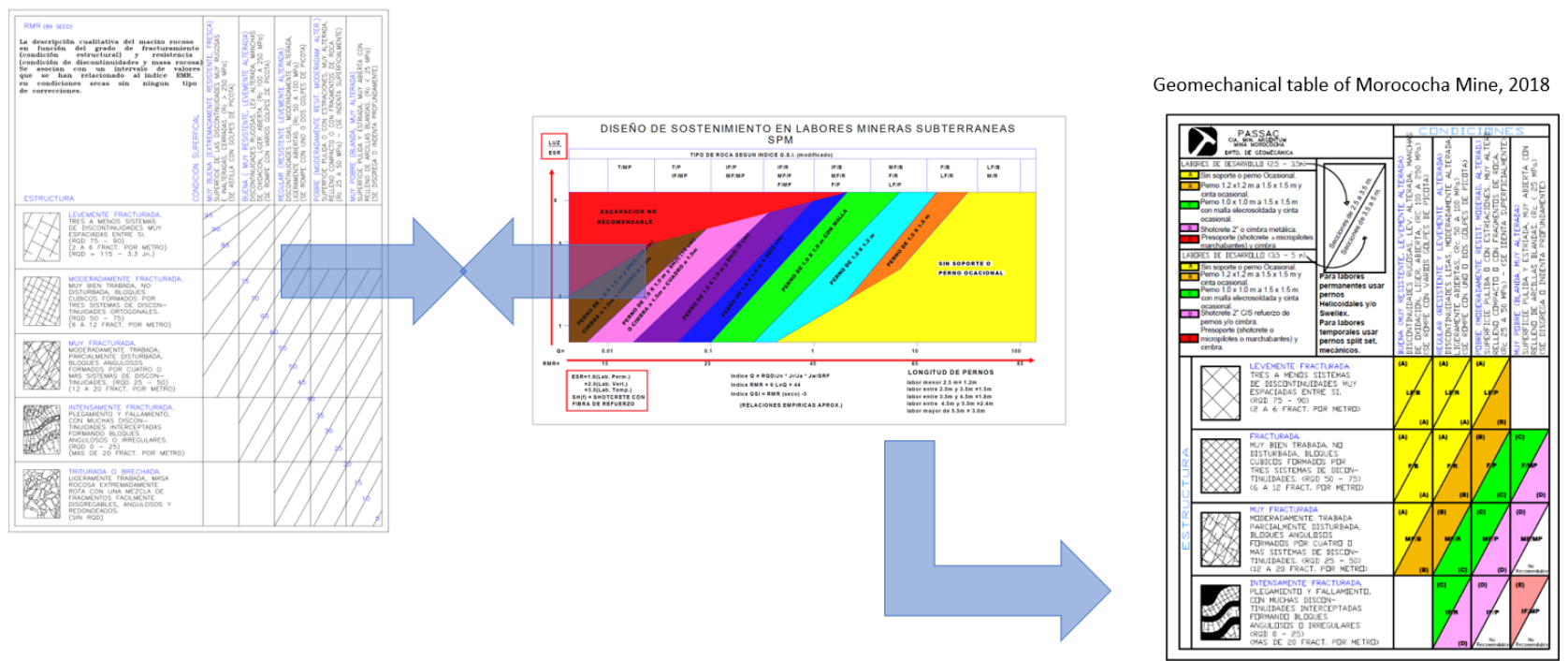

GSI Modified Table + Practical Ground Support table $=$ Geomechanical table

Figure 4 Construction of the Geomechanical Table used in Peruvian underground mines. The Geomechanical Table is the result of the combination of the GSI table and the Practical Ground Support in Mining (SPM) table

The procedure to use the Geomechanical Table starts with a ground evaluation. After the verification of the ventilation and the scaling procedures of the excavations, the type of rock mass is defined. Thus, a measure tape is used to account for the number of fractures per metre; and a hammer is used to measure the rock strength. At the same time, the surface condition of the structure is evaluated. Once these parameters are determined, the type of rock mass can be identified in the Geomechanical Table and the type of support is defined using the colour assigned to this rock mass classification. It is very important to use the right table for the excavation. For example, if the rock mass of an excavation presents 15 fractures per metre and the rock breaks with more than one blow of the flat end of the geologic hammer, the rock mass is classified as very blocky/fair (MF/R in Spanish) in the Morococha Geomechanical Table used in 2008 (Figure 5). Considering a development of a section of $4.0 \times 4.0 \mathrm{~m}$, the support recommended for this excavation corresponds to the colour green that represents rockbolt support in a square pattern of $1.0 \times 1.0 \mathrm{~m}$ plus metallic mesh. However, the correlation between the rock mass indices considers dry conditions and medium stresses. It was decided that, if one of these conditions is not accomplished in the excavations, the type of rock support to be chosen will be the following in high order. Thus, in the previous example, if the excavations 
present water, the assigned support will be the one corresponding to the next pink colour (shotcrete with fibre of $5.0 \mathrm{~cm}$ of thickness plus rockbolt in a square pattern of $1.0 \times 1.0 \mathrm{~m}$ or metallic arcs).

15 fractures per meter, the rock breaks with more than one blow of flat end of the geologic hammer.

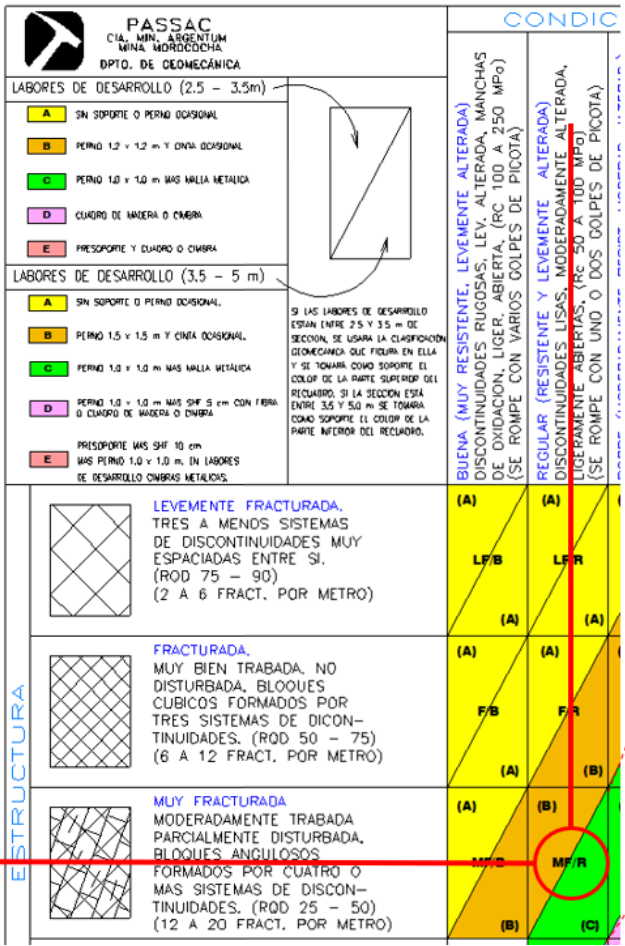

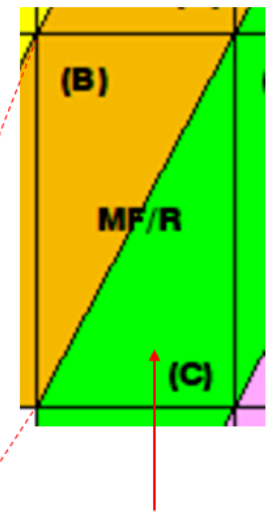

GSI-index corresponds to a MF/R and the support recommended to this kind of rock mass corresponds to the green color (excavation of 4.0 m spam)

Figure 5 Example of the application of the Geomechanical Table used in Morococha Mine during the period 2005-2008. Once the rock mass classification is identified, the ground support recommended for the excavation is defined by the colour of the corresponding box. The upper colour (orange) is used for excavation until $3.5 \mathrm{~m}$ of span and the lower colour (green) is used for excavations with a span between 3.5 and $5.0 \mathrm{~m}$

All of these simplifications allowed the introduction of the GSI in underground mining excavations. To ensure success of implementation, the mining manager support was important to enforce the use of Geomechanical Tables by all engineers and workers of all levels, to provide constant training and to apply penalties if the geomechanical engineers' recommendations were not followed. Geomechanical Tables were included as part of the worker safety equipment and therefore everyone had to carry it and use it. In 2008, Morococha Mine reduced the number of fatal accidents due to rockfall to zero.

\section{$4 \quad$ Results and application of the Geological Strength Index tables in underground mines}

Morococha Mine started the implementation of a geomechanical department at the end of 2004 and Geomechanical Tables were introduced in underground excavations for the different operations and types of excavations. The tables were made considering the most common types of rock mass encountered on the property (Figure 6) and new types of ground supports were included in order to reduce the mine cycle. The reduction of wood usage was important to accelerate the mining cycle, to increment the spans and to initiate the transformation of the mine from conventional to mechanised operation. Figure 7 shows some types of ground support used in Morococha Mine during 2005-2010. The use of split sets, metallic arc, shotcrete and, in narrow excavations, wood trunk plus jackpot (when the quality of the walls allowed it) were introduced and included in the Geomechanical Table. The Geomechanical Table allowed the mine workers to reduce the cost of the ground support, to manage the ground condition and to reduce the number of accidents. Thus, excavations become safer due to the time reduction in which the excavation is opened. 

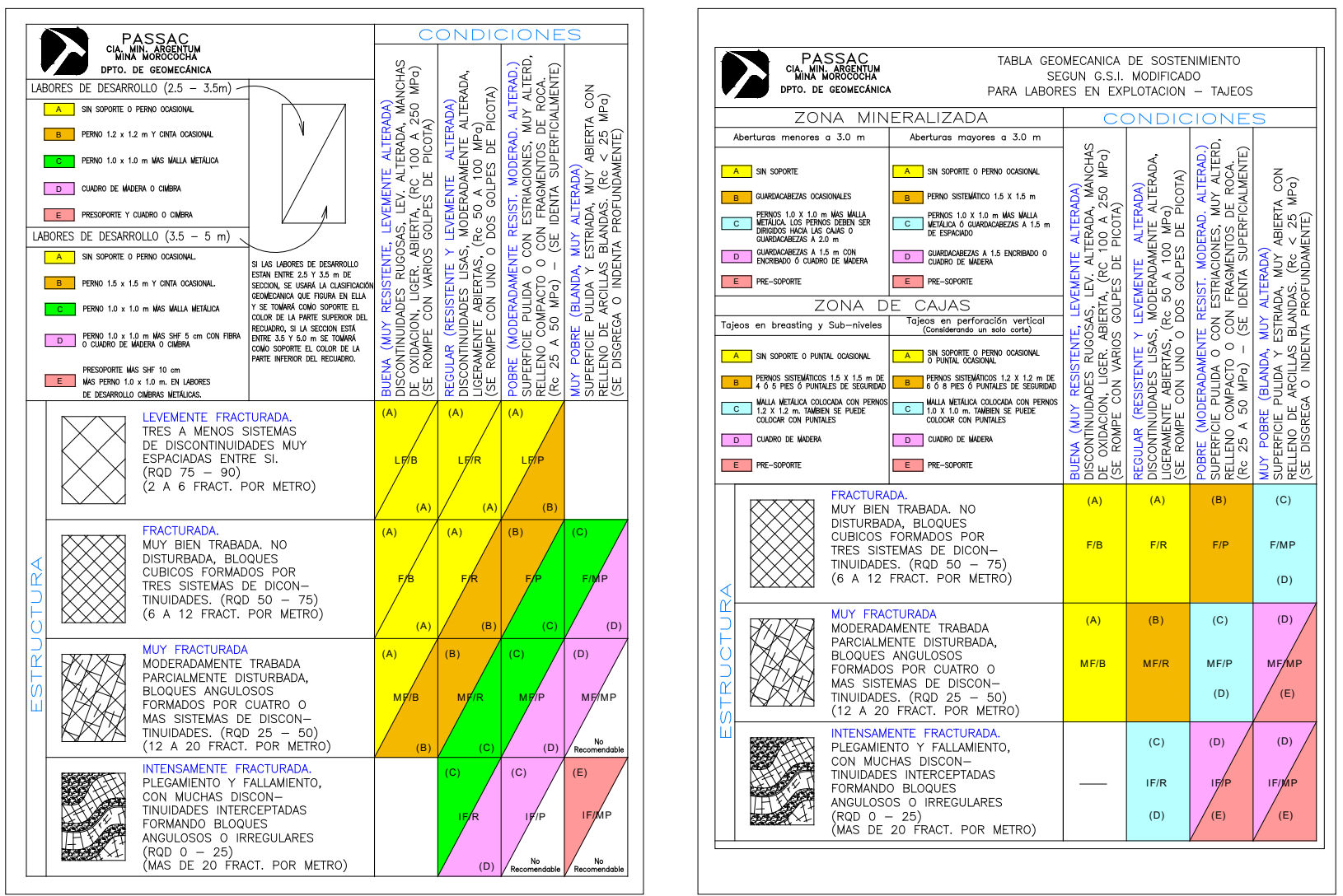

Figure 6 Geomechanical Table used in Morococha Mine during 2005-2008. The first table is used for developments (permanent excavations) and the second one for stopes (temporary excavation) (tables in Spanish)
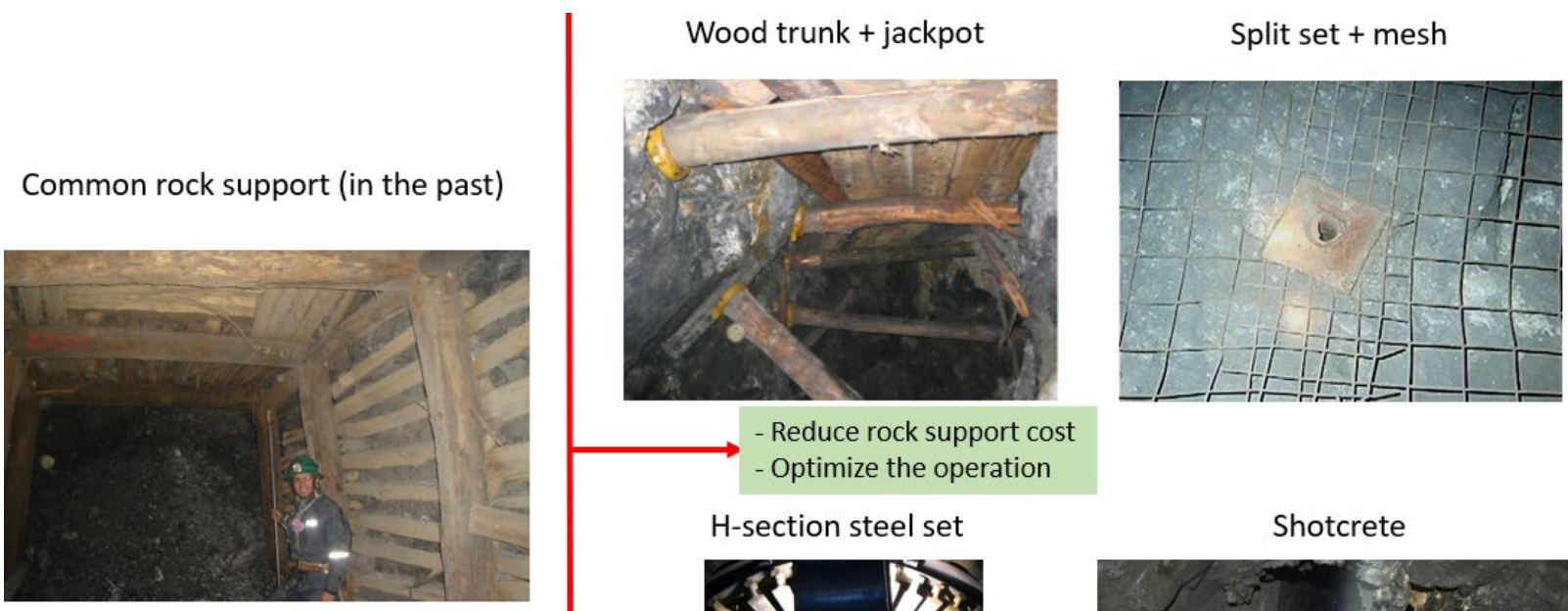

$\mathrm{H}$-section steel set

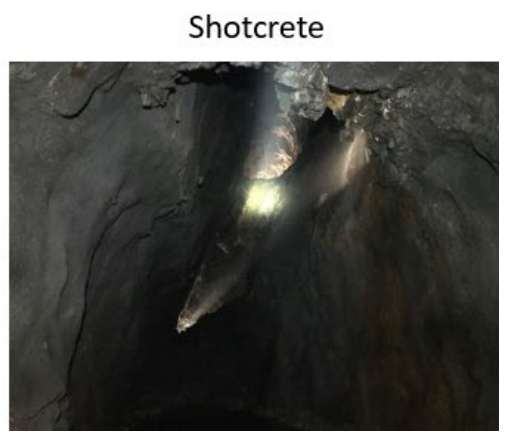

Figure 7 Comparison of the common rock support used in the past at Morococha Mine, with the new types of ground support introduced in 2005 using the Geomechanical Table 
The new support types were tested in specific stopes and supervised by the geomechanical engineers. Intensive training was given to workers regarding the use of these types of ground support, as well as the procedures and standards of evaluation of the ground and installation of ground support. The geomechanical department unified all geomechanical procedures using the Geomechanical Table (GSI). Thus, mapping and geomechanical zoning of the mine was done using the GSI (Figure 8(a)). Due to limited time for the geomechanical engineers to map all excavations, a template of the geomechanical supervision of stopes was made (Figure $8(b)$ ). This template contains a sketch of the stope with the rock mass classification and ground support for walls and back in intervals of $5.0 \mathrm{~m}$. If more details are required for a specific stope, the information of the template can be combined with the geological mapping or structural mapping in order to improve the geomechanical interpretations. The integration of the geomechanical information allows obtaining results in a relatively short time, demonstrating that geomechanical departments improve mining operations as well as safety.

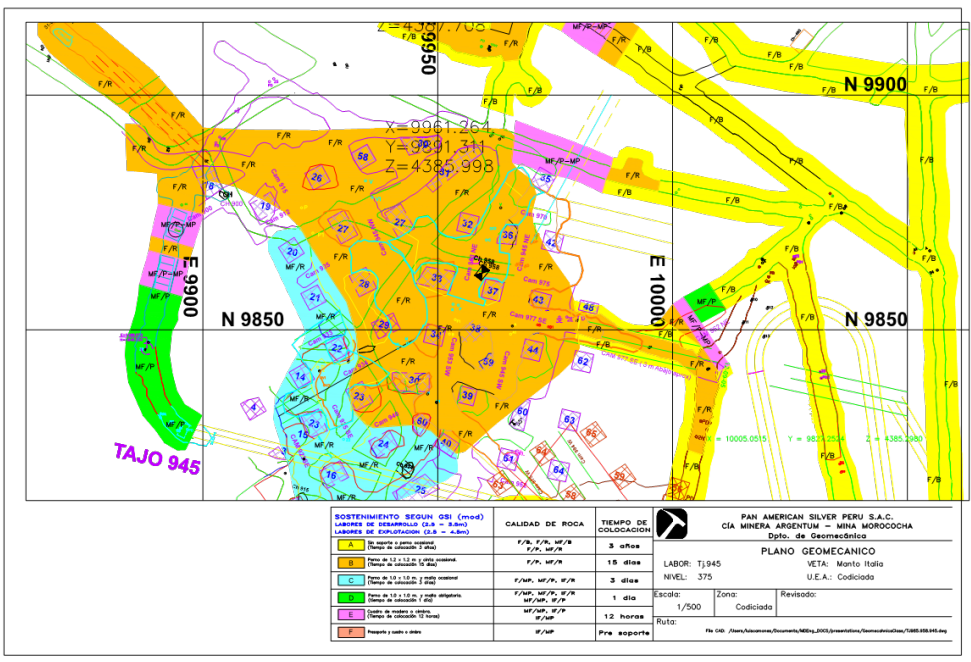

Geomechanical map using the GSI index at Morococha Mine (Peru)

(a)

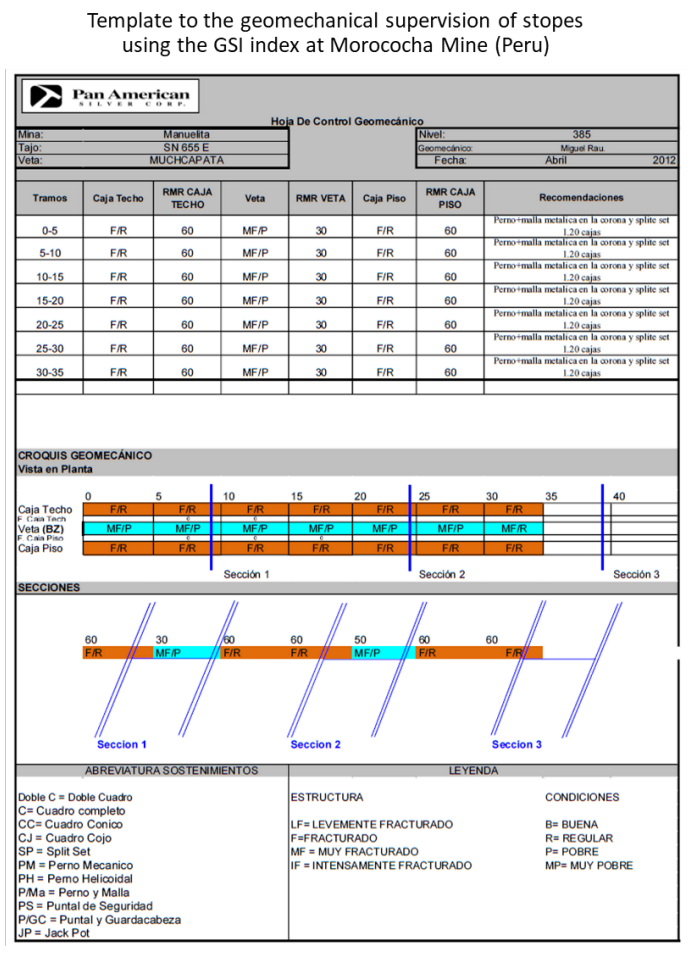

(b)

Figure 8 Unification of the geomechanical procedures using the Geomechanical Table. (a) Mapping using the GSI; (b) Template of the geomechanical supervision of stopes using the GSI

As previously mentioned, the involvement of all workers was very important to the success of the Geomechanical Table implementation. The GSI represents a simple rock mass classification, which can be taught to workers. The training in the use of Geomechanical Table must be frequent and its use is discussed every day during the safety meeting or at any time during work hours. When an engineer or supervisor visits a stope or development, he has to verify that the workers are using the safety equipment correctly, including the Geomechanical Table. If not, the worker is invited to re-training in the use of the Geomechanical Table and he can be penalised according to the safety procedures. Figure 9 shows training in the use of the Geomechanical Table provided by the geomechanical engineer to the workers. This training is performed in the excavations, showing the correct form to assess the quality of rock mass onsite. The constant training allows the workers to evaluate the ground condition avoiding accidents due to rockfall. 

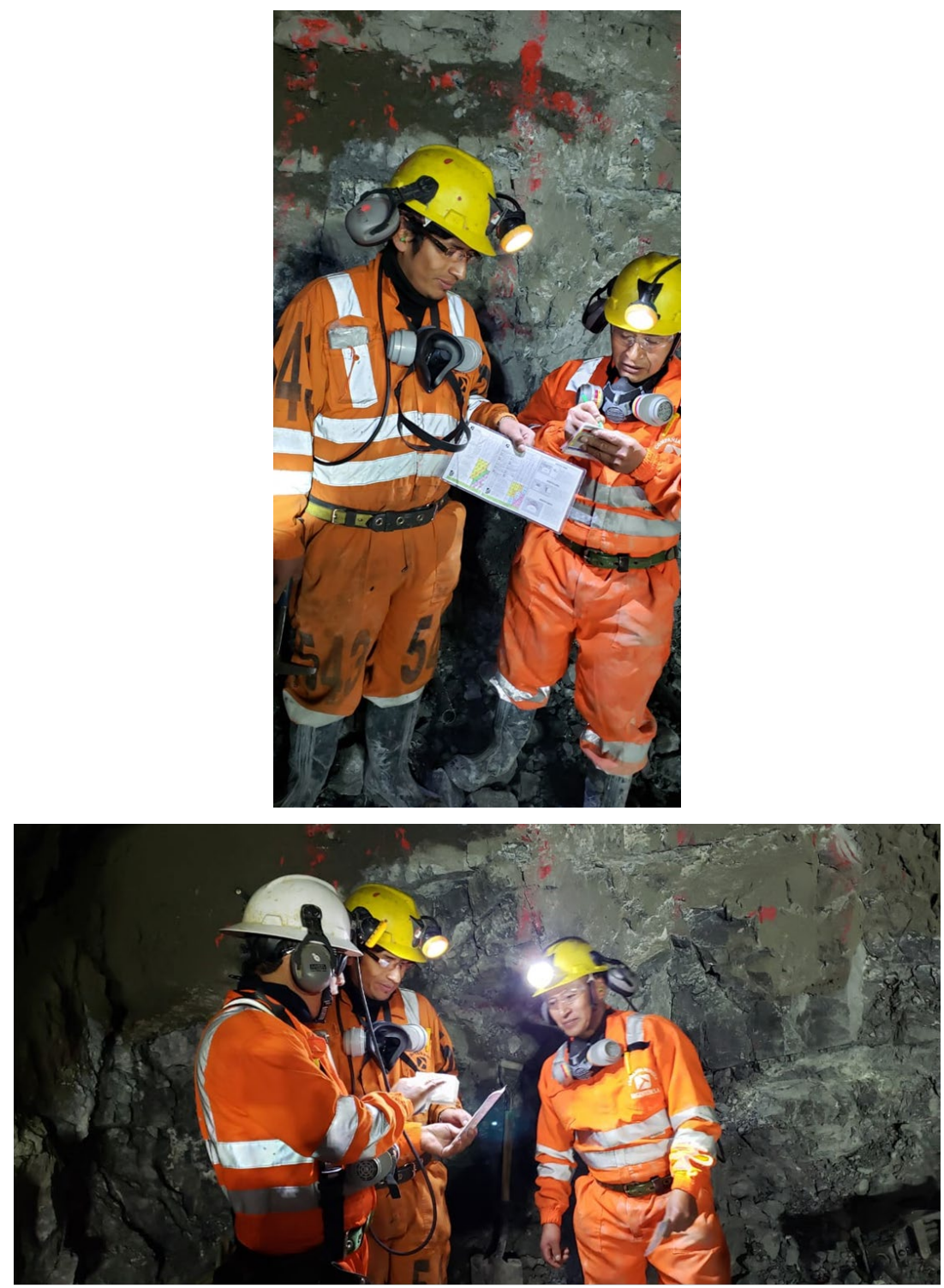

Figure 9 Training in the use of Geomechanical Table must be frequent and all workers have the geomechanical table as a part of safety equipment

The benefits of the geomechanical department implementation and of the Geomechanical Table usage in the reduction of the number of accidents in Morococha Mine can be observed in Figure 10. It shows that the number of fatal accidents due to rockfall is zero since 2010 and the number of non-fatal accidents is decreasing constantly since 2008. The use of the Geomechanical Table combined with other safety systems adopted by the company allowed it to improve the safety conditions of the underground excavations. The number of non-fatal accidents with worker injury is still high. But it can be observed that this number has reduced substantially since 2015 in comparison to the previous years. Also, Figure 11 shows the production of the mine since 2005. The tonnage extracted of the Morococha Mine has increased since the implementation of the geomechanical department and the use of the Geomechanical Table. There are some drops in the production of the mine in the years of 2011 and 2014 due to external factors not related to geomechanical conditions. But after these periods, the production recovers and has been increasing progressively since 2014. Currently, Morococha Mine is a mechanised mine with big stopes and the Geomechanical Table has been adapted to this new condition of the mine operation. 
Fatal accidents in Morococha Mine (2004-2018)

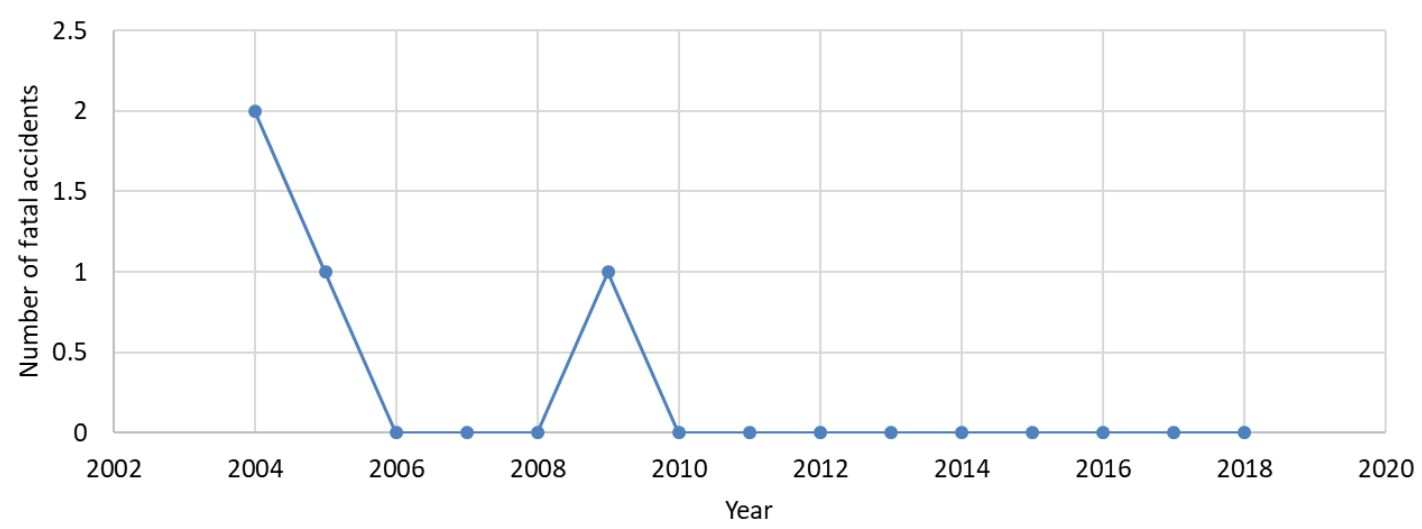

No fatal accidents in Morococha Mine (2008-2018)

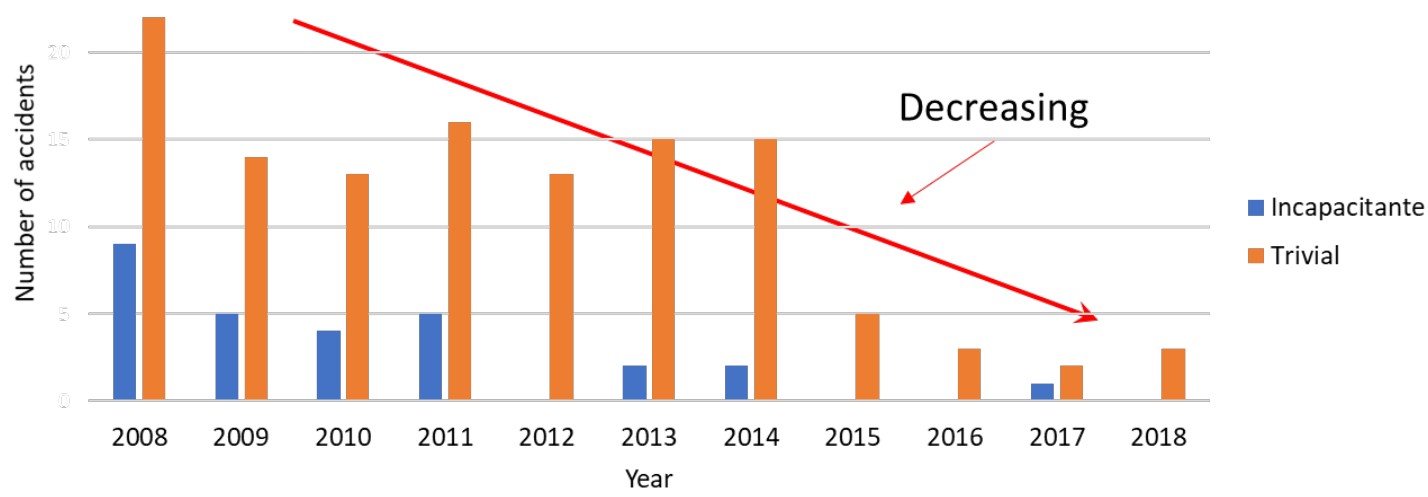

Figure 10 Reduction in the number of accidents due to rockfall in Morococha Mine since the implementation of the geomechanical department and the use of the Geomechanical Table. (top) Number of fatal accidents during the period 2004-2018; (bottom) number of non-fatal accidents during the period 2008-2018, orange bars correspond to minor accidents and blue bars correspond to accidents with some injury

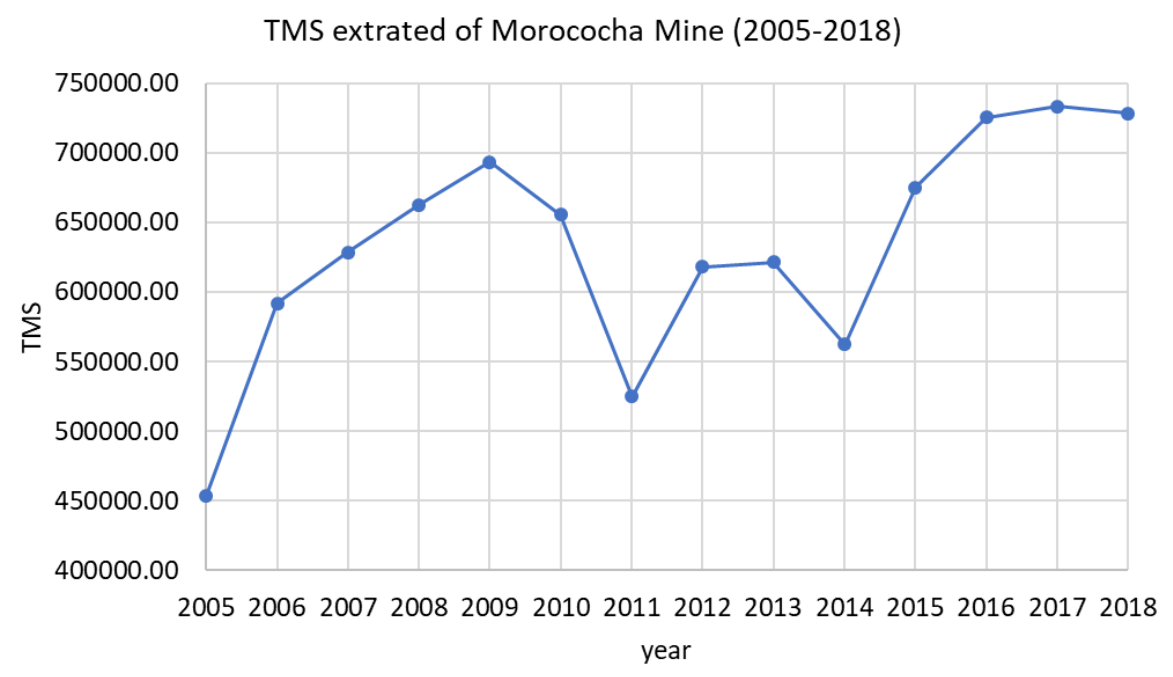

Figure 11 Production of Morococha Mine during 2005-2018 in TMS; in general, there is an increment of the production

In Peruvian underground mining operations, the Geomechanical Table has been accepted as a tool to evaluate the ground condition and to define the ground support recommended for the excavation. Figure 12 shows some examples of Geomechanical Tables used in Arcata, Condestable and Morococha mines. Due to 
the practical use of the GSI to assess qualitatively the geomechanical condition of rock masses, these Geomechanical Tables are currently used in most of Peruvian underground mines. Each mine has its own Geomechanical Table according to the characteristics of its rock masses encountered in the excavations and according to the types of rock supports commonly used. Therefore, the Geomechanical Table of a specific mine cannot be used in another mine. The $Q$ and RMR indices are still used in underground mines to correlate them with the GSI. Also, these indices are used to adjust the GSI table when the geomechanics condition or mining extraction method changes. Only geomechanical engineers are able to modify the Geomechanical Tables and the procedures and standards of the installation of the ground support.

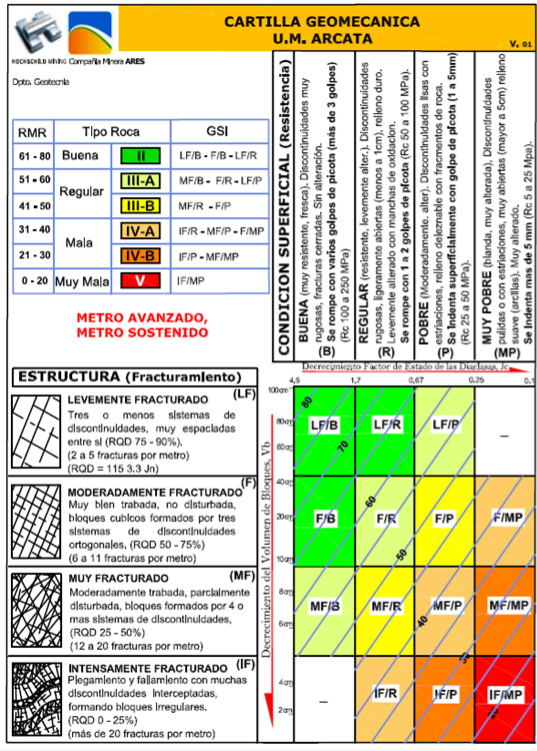

Arcata Mine, 2018

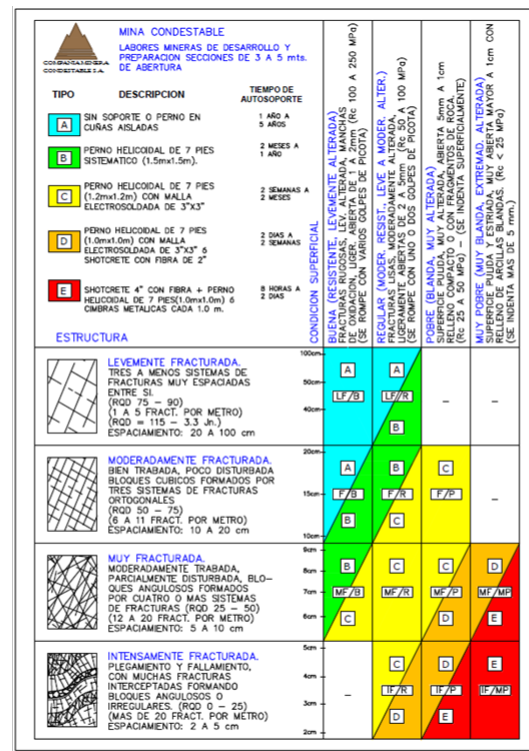

Condestable Mine, 2018

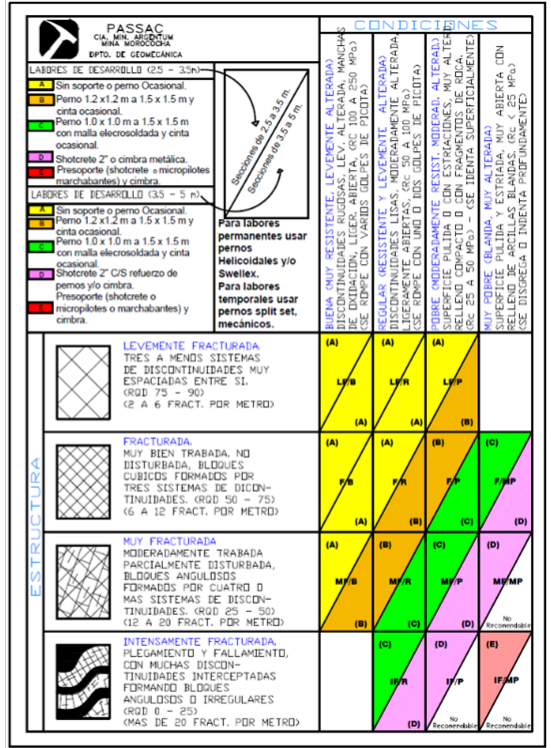

Morococha Mine, 2018

Figure 12 Some examples of Geomechanical Tables used in other underground mines in Peru. Currently, most of the underground mines have adopted the use of the GSI in their operations

\section{Conclusion}

The success of the use of Geomechanical Table in underground Peruvian mines is due to its ease understanding by the workers. This qualitative rock mass classification allows the rock mass conditions to be evaluated quickly, allows the ground support requirements to be defined and provides geomechanical information that can be correlated to other rock mass classification. The combination of all geomechanical procedures into one geomechanical system has created a consistent geomechanical database of the mine, standardised the information collected and enabled the Geomechanical Table to be introduced as a safety tool. The Operation Manager's support has enabled the Geomechanical Table to be included in basic training for all workers and it is now mandatory in all underground operations. The use of the Geomechanical Table in combination with other safety systems has resulted in the reduction of the number of accidents in underground mines, resulted in the management of excavation safety conditions, as well as in a reduction in the cost of ground support and an increase of productivity. Currently, the Geomechanical Table using the GSI is accepted and used in most of Peruvian underground mines.

\section{Acknowledgement}

The authors would like to thank the engineer Carlos Vallejo for providing his experience and information for this technical work. Also, the authors thank Pan American Silver Peru for the support during the execution of this work. 


\section{References}

Barton, N, Lied, R \& Lunde, J 1974, 'Engineering classification of rock masses for the design of tunnel support', Rock Mechanics, vol. 6, no. 4 , pp. $183-236$.

Bieniawski, ZT 1979, 'The geomechanics classifications in rock engineering applications', Proceedings of the Fourth ISRM Congress, Montreux, Switzerland.

Bieniawski, ZT 1989, Engineering Rock Mass Classifications, Wiley, New York.

Hoek, E \& Brown, ET 1997, 'Practical estimates of rock mass strength', International Journal of Rock Mechanics and Mining Sciences, vol. 34, no. 8, pp. 1165-1186.

Hoek, E, Kaiser, P \& Bawden, W 1995, 'Support of underground excavations in hard rock', A.A. Balkema, Rotterdam.

Vallejo, C 1999, 'Descripción y aplicaciones prácticas del Índice G.S.I. (Geological Strength Index) en excavaciones subterráneas (in Spanish)', Proceedings of XII National Congress of Civil Engineering, Peruvian Civil Engineering Council - Council of Huanuco.

Vallejo, C 2002, 'Aplicaciones del Indice G.S.I. (Geological Strength Index) para el Mapeo Geomecánico y la definición del Sostenimiento de laboures Mineras subterráneas (in Spanish)', Proceedings of XI Peruvian Congress of Geology, Lima. 